\title{
Assessment of WebSEM K-12 Outreach Efforts
}

\author{
A. E. Chumbley, L. S. Chumbley
}

Materials Science and Engineering, Iowa State University, 2220 Hoover Hall, Ames, IA 50011

The WebSEM is an on-line scanning electron microscope specifically adapted for use by educators in elementary and secondary schools [1]. The microscope is part of Project ExCEL [2], an NSF funded program aimed at bringing high technology equipment into K-12 classrooms, and has been in operation for approximately 7 years. It is accessed through a simple web page utilizing a high-speed connection. Since it's inception the WebSEM has been used by educators in 10 states and two foreign countries. During development the major issues were technical in nature, involving proper design and implementation of the WebSEM interface. This involved creation of the control panel with user-friendly buttons, computer set-up needs at the school, and solving the problem of sending large files across the Internet in a rapid and efficient manner to schools that did not possess the most up-to-date computer resources or personnel. In recent years the leading concern has been how to get educators to find and use this technology. It was once thought "If you build it, they will come." This sentiment is great for a movie but unrealistic in the world of education, and numerous efforts have been tried to advertise the WebSEM, train educators, and increase and maintain a stable user base. These efforts have included working with pre-service teachers, offering summer workshops to inservice teachers and educators, including financial incentives for planning and scheduling a lesson. Presentations have been given to Area Education Association (AEA) specialists, at AEA meetings, and at the Iowa Science Teachers Convention as a means of reaching science educators.

While these efforts result in temporary increases in WebSEM useage, over time the number of lessons has remained steady. Thus, if one considers the total number of lessons conducted, the majority of educators who have used the WebSEM have been one-time clients. Assessments have been conducted in an effort to find out why educators have, or have not, used the WebSEM in their classrooms. When asked, a survey of past and present clients found that almost all respondents were very positive on the experience and thought it worthwhile. However, the fact remains that most teachers do not continue to schedule lessons on a yearly basis. Three main reasons have been identified as to why teachers discontinue use of the WebSEM after their initial exposure. The first is that they are unable to 'fit' the WebSEM into their curriculum on a regular basis. Statements to the effect that teachers have too much to teach in too little time were common, and the WebSEM is considered an extra that is easy to skip. The second is the difficulty in scheduling the WebSEM into the school curriculum. Specifically, teachers have trouble scheduling in advance because of the changeable nature of public education. Others have found that they cannot schedule all of their class sections to use the school's computer lab during class time. The third reason for not using the WebSEM is local technology difficulties. Often the school's computer personnel are unwilling to allow any changes to the network/firewall for fear that they would compromise their system. Other, less technically savvy instructors with very old computers said that it was too much work setting up their classroom computer for the WebSEM lesson.

Assessment concerning why teachers do use the WebSEM has provided some interesting insights, and conclusions can be drawn by looking at the client history and demographics. Most of the clients who have used the WebSEM a number of times are 'veteran' teachers with 10 or more years of 
teaching experience. Such educators may be expected to be more comfortable with their curriculum and have the time and inclination to pursue activities that enhance their classroom experiences. Repeat clients also tend to be more comfortable with computer technology and teach in schools that support and promote infusing technology into the classroom. While most repeat clients admit to using the WebSEM for the "wow" effect as part of the general goal of exposing the students to technology, a small number have been conducting more advanced classes on specific topics [3], or allowing students to pursue independent study options using the technology.

It is apparent from surveyed answers that many of the local problems associated with using the WebSEM cannot be solved on a general basis for all potential clients. It is also obvious that teachers, even repeat clients, view SEM use as an extra to their standard curriculum. If WebSEM use is to grow then it must be shown as a tool for teaching concepts already in the standard curriculum that can be employed with minimal effort. Lesson plans with curriculum standards have been provided on the Project ExCEL web site and some teachers have used these lessons plans for inspiration, adapting them to their own needs. Few have ever been used as written, and continued effort in writing complete lesson plans is deemed to be of little use. However, circulating teachers' ideas and providing inspiration for them to develop their own lessons involving the WebSEM may be more profitable. To this end a monthly e-mail with ideas and inspiration for WebSEM lessons is being sent. It is purposely formatted to allow the teachers to print and place these lesson ideas directly into their files for future use at an appropriate time in their curriculum. As this is a new initiative, no data is yet available on how this will affect WebSEM usage.

Continued e-mail reminders will only reach teachers that currently are, or have been, clients. As teachers move from school to school, or retire, these numbers will decline unless new clients are found. Continued advertising and promotion is necessary, and past promotions through summer courses and teacher conventions has always produced new clients. However, such efforts require a continuing source of funds that is not available. Use of the WebSEM has always been free of charge to educators and NSF does not provide funds for continuing a project of this type. Thus, the possibility of future large-scale efforts is limited.

In conclusion, the WebSEM remains a useful tool for bringing the field of electron microscopy into the classroom. However, it is hampered by local school constraints, high demands on teacher time, and a lack of funding for providing better advertising and assistance to teachers. It can only be hoped that as schools continue to evolve and both teachers and students become more technology savvy, instruments such as the WebSEM will eventually be used to their fullest potential.

\section{References}

[1] L.S. Chumbley, G. Cassucio, D. Kritikos, H. Lentz, C. Mannes, K. Mehta, Micro. Res. and Tech. 56 (6) (2002) 454-461.

[2] L.S. Chumbley, C.P. Hargrave, K. Constant, B. Hand, T. Andre, E.A. Thompson, J Eng Ed 91

(2) (2002) 203-210.

[3] J. Sharp, K. Hoiberg, and S. Chumbley, Science \& Children 41 (2) (2003) 33-37. 